Chronic Obstructive Pulmonary Diseases:

Journal of the COPD Foundation

\author{
Original Research
}

\title{
Endobronchial Coils Versus Lung Volume Reduction Surgery or Medical Therapy for Treatment of Advanced Homogenous Emphysema
}

Nathaniel Marchetti, DO ${ }^{1}$ Theresa Kaufman, DO ${ }^{1}$ Divay Chandra, MD ${ }^{2}$ Felix J. Herth, MD ${ }^{3}$ Pallav L. Shah, MD ${ }^{4}$ Dirk-Jan Slebos, $\mathrm{MD}^{5}$ Chandra Dass, $\mathrm{MD}^{1}$ Stephen Bicknell, MD ${ }^{6}$ Stefan H. Blaas, MD ${ }^{7}$ Michael Pfeifer, $\mathrm{MD}^{7}$ Franz Stanzell, $\mathrm{MD}^{8}$ Christian Witt, $\mathrm{MD}^{9}$ Gaetan Deslee, $\mathrm{MD}^{10}$ Wolfgang Gesierich, $\mathrm{MD}^{11}$ Martin Hetzel, MD ${ }^{12}$ Romain Kessler, $\mathrm{MD}^{13}$ Sylvie Leroy, $\mathrm{MD}^{14}$ Juergen Hetzel, $\mathrm{MD}^{15}$

Frank C. Sciurba, $\mathrm{MD}^{2}$ and Gerard J. Criner, $\mathrm{MD}^{1}$

\section{Abstract}

Rationale: Bronchoscopic lung volume reduction utilizing shape-memory nitinol endobronchial coils (EBC) may be safer and more effective in severely hyperinflated homogeneous emphysema compared to medical therapy or lung volume reduction surgery (LVRS).

Methods: The effect of bilateral EBC in patients with homogeneous emphysema on spirometry, lung volumes and survival was compared to patients with homogeneous emphysema randomized in the National Emphysema Treatment Trial (NETT) to LVRS or medical therapy. NETT participants were selected to match EBC participants in age, baseline spirometry, and gender. Outcomes were compared from baseline, at 6 and 12 months.

Results: There were no significant baseline differences in gender in the EBC, NETT-LVRS or medical treatment patients. At baseline no differences existed between EBC and NETT-LVRS patients in forced expiratory volume in 1 second $\left(F E V_{1}\right)$ or total lung capacity (TLC) \%-predicted; residual volume (RV) and diffusing capacity of the lung for carbon monoxide (DLco) \%-predicted were higher in the EBC group compared to NETT-LVRS $(p<0.001)$. Compared to the medical treatment group, EBC produced greater improvements in FEV 1 and RV but not TLC at 6 months. FEV 1 and $\mathrm{RV}$ in the EBC group remained significantly improved at 12 -months compared to the medical treatment group. While all 3 therapies improved quality of life, survival at 12 months with EBC or medical therapy was greater than NETT-LVRS.

Conclusion: EBC may be a potential therapeutic option in patients with severe homogeneous emphysema and hyperinflation who are already receiving optimal medical treatment.

Abbreviations: endobronchial coils, EBC; lung volume reduction surgery, LRVS; National Emphysema Treatment Trial, NETT; forced expiratory volume in 1 second, $\mathbf{F E V}_{\mathbf{1}}$; total lung capacity, TLC; residual volume, RV; diffusing capacity of the lung for carbon monoxide, DLCO; St George's Respiratory Questionnaire, SGRQ; computed tomography, CT; standard deviation, SD; analysis of variance, ANOVA; forced vital capacity, FVC; minimal clinically important difference, MCID

Funding Support: None

Date of Acceptance: Novemebr 8, 2017

Citation: Marchetti N, Kaufman T, Chandra D, et al. Endobronchial coils versus lung volume reduction surgery or medical therapy for treatment of advanced homogenous emphysema. Chronic Obstr Pulm Dis. 2018;5(2):87-96. doi: https://doi.org/10.15326/ jcopdf.5.2.2017.0134 
1 Lewis Katz School of Medicine at Temple University, Philadelphia, Pennsylvania

2 University of Pittsburgh Medical Center, Pittsburgh, Pennsylvania

3 Thoraxklinik, University of Heidelberg, Heidelberg, Germany

4 The National Institute for Health Research Respiratory Biomedical Research Unit, Royal Brompton \& Harefield NHS Foundation Trust and Imperial College, London, United Kingdom

5 University Medical Center Groningen, University of Groningen, The Netherlands

6 Gartnaval General Hospital, Glasgow, Scotland

7 Klinikum Donaustauf, Donaustauf, Germany

8 Lungenklinik, Hemer, Germany

9 Campus Charité Mitte, Berlin, Germany

10 Service de Pneumologie Hôpital Maison Blanche, INSERM 903, Reims, France

11 Asklepios-Fachkliniken, Muenchen-Gauting, Germany

12 Krankenhaus von Roten Kreuz, Stuttgart, Germany

13 CHU de Strasbourg - NHC, Strasbourg, France

14 FHU OncoAge Côte d'Azur University, Nice, France

15 Department of Internal Medicine II-Pneumology, University Hospital, Teubingen, Germany

Address correspondence to:

Nathaniel Marchetti, D.O.

Associate Professor of Medicine

Department of Thoracic Medicine and Surgery

Lewis Katz School of Medicine at Temple University

745 Parkinson Pavilion

3401 North Broad Street

Philadelphia, Pa 19140

Phone: 215-707-9929

Email: nathaniel.marchetti@tuhs.temple.edu

\section{Keywords:}

lung volume reduction; emphysema; lung volume reduction coils

\section{Introduction}

Hyperinflation is commonly associated with advanced homogenous emphysema and causes significant morbidity and mortality. Hyperinflation may adversely affect lung and chest wall mechanics and impair respiratory muscle performance. ${ }^{1,2}$ Because of these adverse physiological effects, hyperinflation significantly contributes to shortness of breath, impaired quality of life, development of respiratory failure and increased mortality. ${ }^{3-7}$ Conversely, hyperinflation may be reduced with bronchodilators, supplemental oxygen and pulmonary rehabilitation. ${ }^{8-11}$ The most potent approach to treat hyperinflation is lung volume reduction surgery (LVRS). In hyperinflated emphysematous patients, LVRS has been shown to improve lung and respiratory muscle function, exercise performance, quality of life and in select patients, mortality. ${ }^{12-14}$

LVRS, however, is associated with substantial morbidity and mortality. ${ }^{13,15}$ Consequently, the numbers of patients receiving LVRS has steeply declined over the past decade both in the United States and abroad. ${ }^{16}$ Minimally invasive bronchoscopy techniques that can reduce lung volume with less morbidity have been recently reported. One of these techniques uses sub-segmental airway insertion of shape-memory nitinol endobronchial coils (EBC) that are effective independent of the presence of collateral ventilation. Several studies have shown that this technique improves quality of life, lung function and 6-minute walk distance in patients with heterogeneous and homogenous emphysema, ${ }^{17-23}$ and in a small study also in strictly homogeneous emphysema. ${ }^{24}$ Recently, 3 randomized controlled trials enrolled heterogeneous and homogenous emphysema patients, demonstrating a modest exercise improvement following EBC, with substantial improvements in quality of life (St George's Respiratory Questionairre [SGRQ]). In each trial, approximately two-thirds of the participants had homogeneous emphysema. ${ }^{18,21,22}$ Homogenous patients are of particular interest since LVRS increases the risk of death in these patients. ${ }^{15}$ Lung transplantation is the only option other than medical therapy; the latter, even when optimized, fails to produce dramatic improvements or substantially improve survival in patients with advanced emphysema. 16,25

We hypothesized that bronchoscopic lung volume reduction utilizing EBC would be more effective than usual medical care in severely hyperinflated emphysema patients, with fewer complications compared to LVRS.

\section{Methods \\ Patient Population}

We evaluated consecutive patients with homogenous emphysema who underwent bilateral EBC in previously reported clinical trials. ${ }^{17,22,23}$ EBC treatment was targeted to the most emphysematous regions of the lung. We compared them to another cohort of individuals with homogenous emphysema who had been enrolled into the National Emphysema Treatment Trial (NETT). ${ }^{13,26}$ All patients with 
homogeneous emphysema were eligible for inclusion and were selected by matching lung function and sex to the EBC group. NETT was a prospective randomized and controlled multicenter clinical trial that compared LVRS to optimal medical therapy on the co-primary endpoints of survival and maximum exercise performance. ${ }^{26}$

\section{Lung Function and Exercise Tolerance}

Spirometry was obtained pre and post bronchodilator administration. Only post bronchodilator values are reported. Lung volumes were determined post bronchodilator administration by body plethysmography. ${ }^{27,28}$ The 6-minute walk distance (6MWD) test was performed in a well-marked 100-foot corridor by conventional performance standards. ${ }^{29}$

\section{Quality of Life Assessment}

The SGRQ was used to measure disease specific indices of quality of life. The SGRQ consists of symptoms, activity and social impact components and a higher score indicates worse quality of life. The instrument was self-administered according to published standards. ${ }^{30}$

\section{Homogenous Emphysema Determination}

Three independent readers reviewed the EBC baseline chest computed tomography (CT) scans and qualitatively scored them for the degree of emphysema using the NETT protocol: the lungs were divided into 3 separate regions: upper (apex to aortic arch); mid (aortic arch to inferior pulmonary vein); and lower zones (inferior pulmonary vein to diaphragm). ${ }^{13,26} \mathrm{~A}$ difference in qualitative scores $<2$ defined homogenous emphysema by the following scoring system:

$0 \%$ lung destruction $=$ score 0

$1 \%-25 \%$ lung destruction $=$ score 1

$26 \%-50 \%$ lung destruction $=$ score 2

$51 \%-75 \%$ lung destruction $=$ score 3

$75 \%-100 \%$ lung destruction = score 4

If a single lung was homogenous the patient was considered to have homogenous emphysema.

\section{Primary Outcomes}

Changes in post bronchodilator spirometry, lung volumes and survival in EBC patients at 12 months post procedure were the primary outcomes compared to the NETT medical therapy or NETT-LVRS arms.

\section{Data Analyses}

Data is reported as mean \pm standard deviation (Mean \pm SD) unless otherwise indicated. Data was analyzed by analysis of variance (ANOVA) to determine statistical significance. Least mean squares using ANOVA with factors of treatment and baseline values was used in the final determination of statistical significance. A $p<0.05$ was considered statistically significant. Survival analysis was conducted using a Kaplan-Meier analysis.

\section{Results}

\section{Patient Demographics}

Data were comprehensively analyzed for 179 patients (85, EBC; 51, NETT-LVRS; 43, medical treatment) as shown in Table 1. NETT-LVRS and medical treatment patients were slightly older compared to EBC patients $(p<0.01)$. Baseline lung function was similar in all 3 groups except diffusion capacity was lower in the NETT-LVRS group compared to the EBC or medical treatment groups $(p<0.001)$. Baseline 6MWD was highest in the NETT-LVRS group compared to the EBC and medical treatment groups $(p<0.001)$ and baseline quality of life was worse in the EBC compared to the NETT-LVRS or medical treatment groups $(p=0.008)$.

\section{Table 1. Baseline Characteristics}

\begin{tabular}{|l|r|r|r|c} 
& \multicolumn{1}{|c|}{$\begin{array}{c}\text { EBC } \\
n=85\end{array}$} & $\begin{array}{c}\text { NETT- } \\
\text { LVRS } \\
n=51\end{array}$ & $\begin{array}{c}\text { Medical } \\
\text { Treatment } \\
n=43\end{array}$ & $p$ \\
\hline Age, years & $61.0 \pm 8.1$ & $64.2 \pm 4.4$ & $64.0 \pm 4.1$ & $<0.01$ \\
\hline Male Sex, $n$ (\%) & $39(46)$ & $24(47)$ & $29(68)$ & 0.06 \\
\hline FVC, \% predicted & $74.8 \pm 17.0$ & $70.5 \pm 13.4$ & $72.2 \pm 10.8$ & 0.10 \\
\hline FEV, \% predicted & $27.6 \pm 7.3$ & $26.8 \pm 3.8$ & $27.6 \pm 4.3$ & 0.38 \\
\hline FEV $\mathbf{1}$ /FVC, \% & $30.8 \pm 7.8$ & $30.6 \pm 5.9$ & $30.5 \pm 6.0$ & 0.50 \\
\hline TLC, \% predicted & $137.9 \pm 19.0$ & $135.4 \pm 8.9$ & $136.3 \pm 9.3$ & 0.34 \\
\hline RV, \% predicted & $247.3 \pm 55.1$ & $234.2 \pm 26.9$ & $236.6 \pm 28.5$ & 0.09 \\
\hline RV/TLC, \% & $65.8 \pm 8.0$ & $65.1 \pm 7.1$ & $62.4 \pm 5.2$ & 0.61 \\
\hline DLCo, \% predicted & $33.4 \pm 10.6$ & $26.1 \pm 7.2$ & $32.5 \pm 10.1$ & $<0.001$ \\
\hline 6MWD, meters & $310.8 \pm 96.6$ & $371.4 \pm 84.1$ & $342.3 \pm 99.9$ & $<0.001$ \\
\hline SGRQ, total & $60.1 \pm 13.7$ & $53.4 \pm 14.4$ & $53.3 \pm 14.1$ & 0.008 \\
\hline
\end{tabular}

$\mathrm{FVC}=$ functional residual capacity; $\mathrm{FEV}_{1}=$ forced expiratory volume in 1 second; TLC=total lung capacity; $\mathrm{RV}=$ residual volume; $\mathrm{DLCO}=$ diffusion capacity of the lung for carbon dioxide; $6 \mathrm{MWD}=6$-minute walk distance; SGRQ=St George's Respiratory Questionnaire; $\mathrm{EBC}=$ lung volume reduction coil with homogeneous emphysema; NETT LVRS=National Emphysema Treatment Trial lung reduction surgery cohort; NETT medical=National Emphysema Treatment Trial medical treatment cohort with homogeneous emphysema 


\section{Changes in Lung Function and 6-Minute Walk Distance}

Table 2 shows changes in pulmonary function measures in patients at 6 and 12 months post intervention compared to baseline in the EBC, NETTLVRS and medical treatment groups. As shown, there was no significant difference in changes in forced vital capacity (FVC), forced expiratory volume in 1 second (FEV1) and $\mathrm{FEV}_{1} / \mathrm{FVC}$ between groups. There was a trend toward a higher FVC in the EBC group at 12 months $(p=0.08)$.

At 6-months there was a significant decrease in residual volume ( $R V, p=0.002)$ and total lung capacity (TLC, $p<0.001$ ) in both the EBC and NETT-LVRS groups compared to medical therapy. The magnitude of the decline in RV and TLC was greater in NETTLVRS than EBC. At 12 months there remained a significant decline in RV $(p=0.006)$ and TLC $(p<0.001)$ compared to baseline in both the EBC and NETT-LVRS groups compared to medical therapy alone.

Following treatment with EBC, the 6MWD improvement was greater in comparison to the NETTLVRS or medical treatment groups at $6(p<0.001)$ and 12 months ( $p=0.001$, Figure 1).

\section{Changes in Quality of Life}

In all 3 groups, SGRQ total and its subcomponent scores of symptoms, activities, and impacts decreased greater than what is considered the minimal clinically important difference (MCID) evidencing an improved quality of life at 12 months compared to baseline (Table 3). Although not statistically significant, the mean reduction in total SGRQ was greatest following $E B C$ at 12 months when compared to the other groups.

\section{Survival}

Figure 2 shows a Kaplan-Meir survival curve at 12 months following the 3 interventions. EBC and medical treatment groups both showed an increased survival compared to the NETT-LVRS group at 1 year $(p<0.001)$.

\section{Discussion}

Our results demonstrate that placement of endobronchial coils in patients with advanced homogeneous emphysema reduced residual volume, total lung capacity, and increased 6MWD compared to optimal medical therapy. Additionally, placement

\section{Table 2. Changes in Spirometry and Lung Volumes at 6 and 12 Months Post Intervention Compared to Baseline}

\begin{tabular}{|c|c|c|c|c|}
\hline & $E B C(n=85)$ & NETT LVRS $(n=51)$ & NETT Medical $(n=43)$ & $p$ value \\
\hline $\begin{array}{l}\text { Change from Baseline } \\
\text { to } 6 \text { Months }\end{array}$ & $n=77$ & $n=35$ & $n=33$ & \\
\hline FVC(L) & $0.30(0.20$ to 0.39$)$ & 0.20 ( 0.06 to 0.34$)$ & $0.01(-0.14$ to 0.15$)$ & 0.27 \\
\hline FEV $_{1}(\mathbf{L})$ & $0.11(0.07$ to 0.14$)$ & 0.11 ( 0.05 to 0.16$)$ & $0.01(-0.05$ to 0.07$)$ & 0.91 \\
\hline FEV $_{1} /$ FVC & $0.14(-0.92$ to 1.19$)$ & $1.36(-0.20$ to 2.92$)$ & $0.23(-1.37$ to 1.84$)$ & 0.20 \\
\hline RV (L) & $-0.58(-0.74$ to -0.42$)$ & $-1.04(-1.28$ to -0.80$)$ & $0.02(-0.23$ to 0.26$)$ & 0.002 \\
\hline TLC (L) & $-0.27(-0.41$ to -0.12$)$ & $-0.92(-1.14$ to -0.70$)$ & $-0.03(-0.26$ to 0.19$)$ & $<0.001$ \\
\hline RV/TLC (L) & $-5.22(-6.42$ to -4.02$)$ & $-6.56(-8.38$ to -4.75$)$ & $-0.58(-2.48$ to 1.33$)$ & 0.22 \\
\hline $\begin{array}{l}\text { Change from Baseline } \\
\text { to } 6 \text { Months }\end{array}$ & $n=50$ & $n=28$ & $n=31$ & \\
\hline FVC (L) & $0.32(0.19$ to 0.45$)$ & $0.12(-0.05$ to 0.30$)$ & $0.02(-0.15$ to 0.18$)$ & 0.08 \\
\hline FEV $_{1}(\mathbf{L})$ & $0.11(0.05$ to 0.17$)$ & $0.05(-0.03$ to 0.12$)$ & $0.01(-0.07$ to 0.08$)$ & 0.19 \\
\hline $\mathrm{FEV}_{1} / \mathrm{FVC}$ & $-0.13(-1.49$ to 1.22$)$ & $-0.30(-2.10$ to 1.51$)$ & $0.24(-1.46$ to 1.95$)$ & 0.89 \\
\hline RV (L) & $-0.53(-0.74$ to -0.32$)$ & $-1.03(-1.32$ to -0.75$)$ & $-0.08(-0.36$ to 0.19$)$ & 0.006 \\
\hline TLC (L) & $-0.34(-0.53$ to -0.14$)$ & $-0.94(-1.20$ to -0.67$)$ & $-0.11(-0.36$ to 0.15$)$ & $<0.001$ \\
\hline RV/TLC (L) & $-4.14(-5.91$ to -2.37$)$ & $-6.47(-8.88$ to -4.06$)$ & $-0.90(-3.23$ to 1.43$)$ & 0.12 \\
\hline
\end{tabular}




\section{Figure 1. Six-Minute Walk Distance}

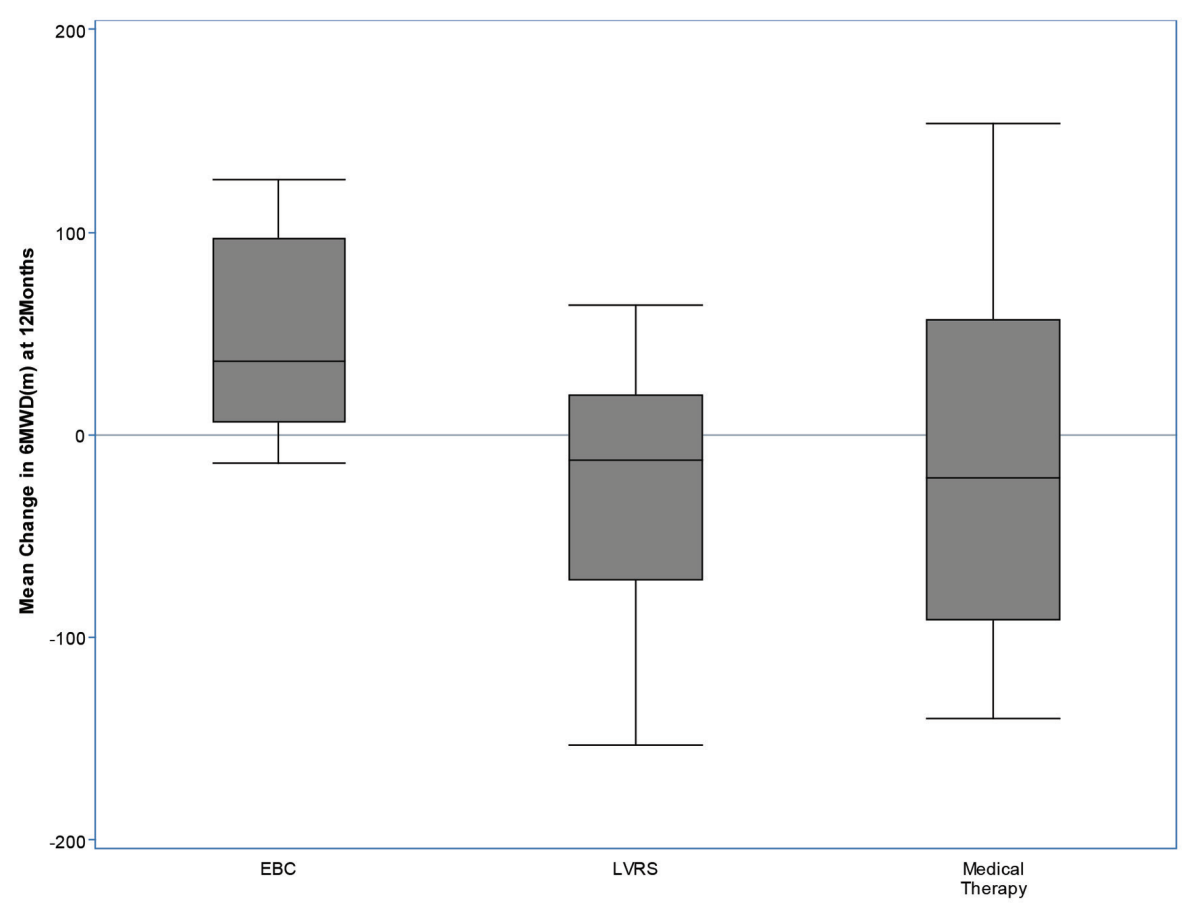

Six-minute walk distance is improved at 6 and 12 months following EBC compared to NETT-LVRS and medical therapy.

$6 \mathrm{MWD}=6$-minute walk distance; $\mathrm{EBC}=$ endobronchial coils; LVRS=long volume reduction surgery

\section{Table 3. Effect of NETT-LVRS, Medical Treatment and EBC on Quality of Life as Measured by Changes in SGRQ at 12 Months Post Randomization to Therapy}

\begin{tabular}{|c|ccc|}
\hline EBC & NETT- & Medical & $p$ \\
$n=85$ & LVRS & Treatment \\
$n=51$ & $n=43$ & value \\
& & $n=4$
\end{tabular}

\begin{tabular}{|c|c|c|c|c|}
\hline $\begin{array}{l}\text { Change in SGRQ } \\
\text { Total Score }\end{array}$ & $\begin{array}{r}-7.19 \\
(-10.88 \text { to }-3.49) \\
\end{array}$ & $\begin{array}{r}-5.78 \\
(-10.42 \text { to }-1.14)\end{array}$ & $\begin{array}{r}-5.17 \\
(-9.87 \text { to }-0.46)\end{array}$ & 0.64 \\
\hline $\begin{array}{l}\text { Change in SGRQ } \\
\text { Symptoms Score }\end{array}$ & $\begin{array}{r}-5.10 \\
(-10.10 \text { to }-0.09)\end{array}$ & $\begin{array}{r}0.03 \\
(-6.29 \text { to } 6.36)\end{array}$ & $\begin{array}{r}-0.80 \\
(-7.21 \text { to } 5.61)\end{array}$ & 0.21 \\
\hline $\begin{array}{l}\text { Change in SGRQ } \\
\text { Activities Score }\end{array}$ & $\begin{array}{r}-5.73 \\
(-10.48 \text { to }-0.99)\end{array}$ & $\begin{array}{r}-7.95 \\
(-13.87 \text { to }-2.04)\end{array}$ & $\begin{array}{r}-6.09 \\
(-12.09 \text { to }-0.09)\end{array}$ & 0.56 \\
\hline $\begin{array}{l}\text { Change in SGRQ } \\
\text { Impacts Score }\end{array}$ & $\begin{array}{r}-7.84 \\
(-11.17 \text { to }-3.88)\end{array}$ & $\begin{array}{r}-7.20 \\
(-12.14 \text { to }-2.25)\end{array}$ & $\begin{array}{r}-6.76 \\
(-11.76 \text { to }-1.75)\end{array}$ & 0.84 \\
\hline
\end{tabular}

SGRQ=St George's Respiratory Questionnaire; $\mathrm{EBC}=$ lung volume reduction coil with homogeneous emphysema; NETT LVRS=National Emphysema Treatment Trial lung volume reduction surgery cohort; NETT medical=National Emphysema Treatment Trial medical treatment cohort with homogeneous emphysema of endobronchial coils improved 6MWD and survival compared to LVRS. These data suggest that placement of lung coils that reduce end-expiratory lung volume may be a potential therapeutic option in patients with advanced homogeneous emphysema and hyperinflation who are already receiving optimal medical treatment.

Patients with advanced homogeneous emphysema and severe hyperinflation suffer from significantly increased morbidity and mortality. Data from the NETT show that these patients, despite receiving optimal medical treatment while participating in a clinical trial, have a 5-year mortality of $50 \%$ and significantly reduced exercise tolerance, 6-minute walk performance, and impaired quality of life. ${ }^{13-16}$ Furthermore, LVRS in this patient group produces no significant improvements in lung function, maximum exercise or 6MWD and is associated with increased mortality. ${ }^{15}$ Bronchodilators, pulmonary rehabilitation and supplemental oxygen are the mainstays of treatment for this group despite marginal effectiveness. A previous bronchoscopic intervention study investigating the airway bypass approach in homogeneous emphysema patients showed no efficacy 6 months after treatment. ${ }^{31}$ Therefore, other than lung transplantation, patients with advanced homogenous emphysema have no effective treatment options. ${ }^{16,25}$

Initial studies examining the impact of endobronchial coils to improve outcomes in severe emphysema have shown benefit in patients with both heterogeneous and homogenous emphysema. Benefits have included improvements in lung function, 6MWD and quality of life with lung coil placement compared to usual care. $^{17,20,23,24}$ However, these were non-controlled studies. Shah et al showed substantial improvement in exercise capacity and quality of life at 


\section{Figure 2. Kaplan-Meir Survival Curve at 12 months Following the Three Interventions}

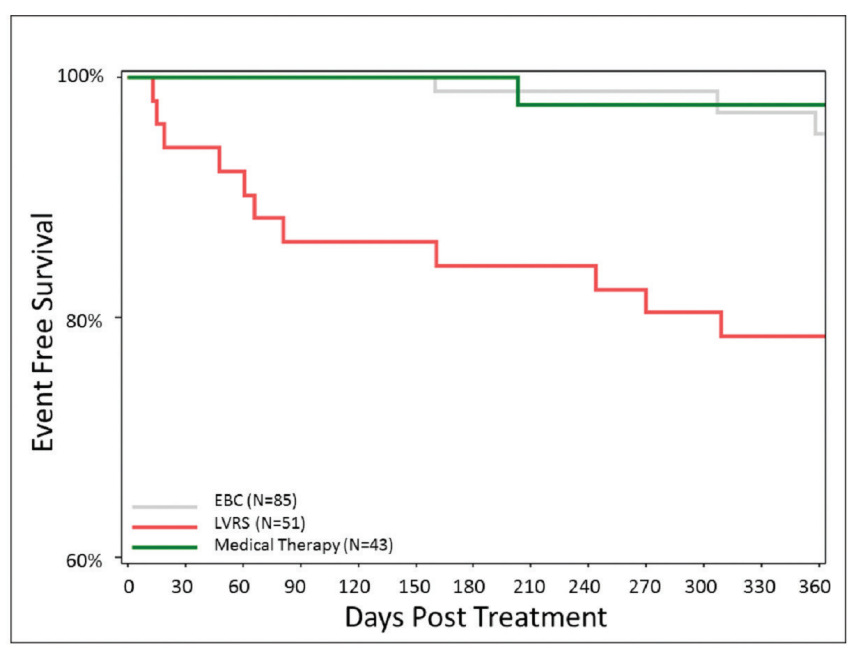

EBC and NETT medical groups show a comparable and increased survival compared to the NETT LVRS group at one year $(p<0.001)$.

$\mathrm{EBC}=$ endobronchial coils; LVRS=long volume reduction surgery

3 months compared to medical treatment with coil placement in a small randomized, controlled study that included both heterogeneous and homogeneous emphysema patients. ${ }^{22}$ Two larger randomized, controlled studies comparing EBC to medical therapy were recently completed in which approximately twothirds of the population in each study had severe homogenous emphysema. ${ }^{18,21}$ Overall, coil treatment showed modest improvements in 6MWD, FEV 1 and lung volumes compared to medical therapy. ${ }^{18,21}$ Our findings offer further support that EBC may benefit patients with homogeneous emphysema for whom few other options are available.

A recent controlled trial using one-way endobronchial valves demonstrated modest improvements in $\mathrm{FEV}_{1}$, quality of life and 6MWD in patients with homogeneous disease. ${ }^{32}$ In previously published lung reduction trials using bronchoscopic techniques designed to reduce lung volume by atelectasis (endobronchial one-way valves) or fibrosis (lung sclerosant or vapor), patients with very heterogeneous disease had a stronger response than those with less heterogeneous or homogenous disease. ${ }^{33-35}$ This is logical since removal of hyperinflated, diseased regions in heterogeneous patients allows more preserved lung tissue to re-expand, while removal of marginally viable lung in homogenous patients may result in expansion of similarly diseased tissue and overall worse functional status. Accordingly, our study shows that patients undergoing EBC had less reduction in residual volume compared to those who underwent LVRS, although 6MWD and survival was improved. Several factors may account for this seemingly disparate outcome between less volume decrease but greater improvements in 6MWD and improved survival. Although LVRS is a more potent lung reduction approach, its increased cardiorespiratory morbidity and mortality outweighs its therapeutic benefit in patients with severe homogeneous emphysema. The post LVRS period is complicated by the need for prolonged acute hospitalization and subacute care secondary to cardiorespiratory complications hallmarked by the ubiquitous presence of air leaks, pneumonia, cardiac arrhythmias, and respiratory failure that may negatively impact 6MWD performance. ${ }^{13,15}$ In contrast, homogeneous patients with severe emphysema who undergo EBC suffer from fewer and less severe cardiorespiratory complications allowing patients to improve their functional status post intervention.

In addition, EBC may improve 6MWD by enhancing cardiac performance as a result of decreased hyperinflation. Recent data show the impact of hyperinflation on impairing cardiac function. ${ }^{36-39}$ Similar beneficial cardiovascular effects of LVRS have been demonstrated by others. ${ }^{40-44}$ Furthermore, lung volume reduction improves chest wall asynchrony and oxygen uptake kinetics. ${ }^{45,46}$ These physiologic benefits in aggregate may contribute to the improvement in 6MWD distance as well as survival that we report in the EBC cohort.

Our study is limited because of its retrospective design, and comparison of patients who underwent coil implantation in studies separate from patients who underwent optimal medical treatment and lung volume reduction surgery in the NETT. Although we carefully matched individuals based on their lung function and degree of hyperinflation, there were differences in age, diffusion capacity and gender that we could not control. Additionally, the NETT was conducted from 1998 to 2003. Changes in medical treatment have occurred since NETT compared to the era of the coil implantation studies that have only been recently conducted. Another limitation is that participants did not have standardized care pre and post procedure due to the retrospective nature of the study and difference in available medical therapy. However, a strength of our 
study is that we compared data that was prospectively collected in prior well-conducted studies in a patient group that requires novel therapies because of their high morbidity and mortality.

In summary, our data suggest that lung volume reduction via lung coil implantation may be a better alternative than LVRS to improve outcomes in patients with severe hyperinflation and homogeneous emphysema. Future prospective investigation is warranted.

\section{Acknowledgements}

Author contributions: NM, FCS, GJC contributed to the study's conception and design. NM, TK, DC, FJH, PLS, DS, CD, SB, SHB, MP, FS, CW, GD, WG, MH, RK, SL, JH, FCS, GJC contributed to data acquisition/ analyses and interpretation. NM, DC, FJH, PLS, DS, CD, FCS, GJC contributed to the writing and substantial revisions of manuscript.

\section{Declaration of Interest}

Authors NM, TK, DC, CD, SB, MP, FS, CW, SL and JH have nothing to disclose. FJH reports personal fees from Pulmonx, Uptake, BTG, and Olympus outside the submitted work. PLS reports personal fees from Broncus, Creo Medical, Holairia, Olympus, Medtronic and PneumRX/BTG as consultant on a scientific advisory board and also reports other support: a sponsorship to Imperial College for a bronchoscopy course by from ERBE, Cook medical, Medtronic, Boston Scientific, Aquilant, Broncus, Pulmonx, Olympus, \& PneumRX outside the submitted work. DS reports grants, personal fees, non-financial support and other from PneumRx/BTG; grants, personal fees, nonfinancial support and other from Holaira, Inc; grants, personal fees, non-financial support and other from CSA Medical; and grants, personal fees, non-financial support and other from PulmonX Inc., outside the submitted work. SHB reports support from PneumRx during the conduct of the study. GD reports personal fees from BTG/pneumRx during the conduct of the study. $\mathrm{MH}$ reports personal fees from BTG during the conduct of the study. RK reports grants from Pulmonx, PneumoRx, and Boston Scientific during the conduct of the study. FCS reports grants and personal fees from PneumRx, and grants from PulmonX and Spiration outside the submitted work. GJC reports grants from Boehringer- Ingelheim, Novartis Astra Zeneca, Respironics, MedImmune, Actelion, Forest, Pearl Ikaria, Aeris, PneumRx, and Pulmonx and other support from HGE Health Care Solutions, Inc, Amirall, Boehringer- Ingelheim, and Holaira, outside the submitted work. 


\section{References}

1. Similowski T, Yan S, Gauthier AP, Macklem PT, Bellemare F. Contractile properties of the human diaphragm during chronic hyperinflation. New Eng J of Med. 1991;325:917-923. doi: https://doi.org/10.1056/NEJM199109263251304

2. Smith J, Bellemare F. Effect of lung volume on in vivo contraction characteristics of human diaphragm. J Appl Physiol. 1987;62(5):1893-1900.

doi: https://doi.org/10.1152/jappl.1987.62.5.1893

3. Casanova C, Cote C, de Torres JP, et al. Inspiratory-to-total lung capacity ratio predicts mortality in patients with chronic obstructive pulmonary disease. Am J Resp Crit Care Med. 2005; 171(6):591-597.

doi: https://doi.org/10.1164/rccm.200407-867OC

4. Garcia-Rio F, Lores V, Mediano O, et al. Daily physical activity in patients with chronic obstructive pulmonary disease is mainly associated with dynamic hyperinflation. Am J Resp Crit Care Med. 2009;180(6):506-512.

doi: https://doi.org/10.1164/rccm.200812-18730C

5. Jubran A, Tobin MJ. Pathophysiologic basis of acute respiratory distress in patients who fail a trial of weaning from mechanical ventilation. Am J Resp Crit Care Med.1997;155(3): 906-915. doi: https://doi.org/10.1164/ajrccm.155.3.9117025

6. O’Donnell DE, Hamilton AL, Webb KA. Sensory-mechanical relationships during high-intensity, constant-work-rate exercise in COPD. J Applied Physiol. 2006;101(4):1025-1035. doi: https://doi.org/10.1152/japplphysiol.01470.2005

7. O'Donnell DE, Revill SM, Webb KA. Dynamic hyperinflation and exercise intolerance in chronic obstructive pulmonary disease. Am J Resp Crit Care Med. 2001;64(5):770-777. doi: https://doi.org/10.1164/ajrccm.164.5.2012122

8. O'Donnell DE, D'Arsigny C, Webb KA. Effects of hyperoxia on ventilatory limitation during exercise in advanced chronic obstructive pulmonary disease. Am J Respir Crit Care Med. 2001;163(4):892-898.

doi: https://doi.org/10.1164/ajrccm.163.4.2007026

9. O'Donnell DE, Fluge T, Gerken F, et al. Effects of tiotropium on lung hyperinflation, dyspnoea and exercise tolerance in COPD. Eur Respir J. 2004;23(6):832-840.

doi: https://doi.org/10.1183/09031936.04.00116004

10. Palange P, Valli G, Onorati P, et al. Effect of heliox on lung dynamic hyperinflation, dyspnea, and exercise endurance capacity in COPD patients. J Applied Physiol. 2004;97:16371642. doi: https://doi.org/10.1152/japplphysiol.01207.2003

11. Porszasz J, Emtner M, Goto S, Somfay A, Whipp BJ, Casaburi R. Exercise training decreases ventilatory requirements and exercise-induced hyperinflation at submaximal intensities in patients with COPD. Chest. 2005;128(4):2025-2034.

doi: https://doi.org/10.1378/chest.128.4.2025
12. Criner GJ, Cordova FC, Furukawa S, et al. Prospective randomized trial comparing bilateral lung volume reduction surgery to pulmonary rehabilitation in severe chronic obstructive pulmonary disease. Am J Respir Crit Care Med. 1999;160(6):2018-2027.

doi: https://doi.org/10.1164/ajrccm.160.6.9902117

13. Fishman A, Martinez F, Naunheim K, et al for the National Emphysema Treatment Trial Research Group. A randomized trial comparing lung-volume-reduction surgery with medical therapy for severe emphysema. New Eng J Med. 2003;348:20592073. doi: https://doi.org/10.1056/NEJMoa030287

14. Naunheim KS, Wood DE, Mohsenifar Z, et al for the National Emphysema Treatment Trial Research Group. Long-term follow-up of patients receiving lung-volume-reduction surgery versus medical therapy for severe emphysema by the National Emphysema Treatment Trial Research Group. Ann Thorac Surg. 2006;82(2):431-443.

doi: https://doi.org/10.1016/j.athoracsur.2006.05.069

15. National Emphysema Treatment Trial Research G. Patients at high risk of death after lung-volume-reduction surgery. New Eng J Med. 2001;345:1075-1083. doi: https://doi.org/10.1056/NEJMoa11798

16. Marchetti N, Criner GJ. Surgical approaches to treating emphysema: Lung volume reduction surgery, bullectomy, and lung transplantation. Semin Respir Crit Care Med. 2015; 36(4):592-608. doi: https://doi.org/10.1055/s-0035-1556064

17. Deslee G, Klooster K, Hetzel M, et al. Lung volume reduction coil treatment for patients with severe emphysema: A European multicentre trial. Thorax. 2014;69(11):980-986. doi: https://doi.org/10.1136/thoraxjnl-2014-205221

18. Deslee G, Mal H, Dutau H, et al. Lung volume reduction coil treatment vs usual care in patients with severe emphysema: The REVOLENS randomized clinical trial. JAMA. 2016;315(2):175184. doi: https://doi.org/10.1001/jama.2015.17821

19. Hartman JE, Klooster K, Gortzak K, ten Hacken NH, Slebos DJ. Long-term follow-up after bronchoscopic lung volume reduction treatment with coils in patients with severe emphysema. Respirology. 2015;20(2):319-326.

doi: https://doi.org/10.1111/resp.12435

20. Herth FJ, Eberhard R, Gompelmann D, Slebos DJ, Ernst A. Bronchoscopic lung volume reduction with a dedicated coil: A clinical pilot study. Ther Adv Respir Dis. 2010;4:225-231. doi: https://doi.org/10.1177/1753465810368553

21. Sciurba FC, Criner GJ, Strange C, et al. Effect of endobronchial coils vs usual care on exercise tolerance in patients with severe emphysema: The RENEW randomized clinical trial. JAMA. 2016;315(20):2178-2189.

doi: https://doi.org/10.1001/jama.2016.6261 
22. Shah PL, Zoumot Z, Singh S, et al. Endobronchial coils for the treatment of severe emphysema with hyperinflation (RESET): A randomised controlled trial. Lancet Respir Med. 2013;1(3):233240. doi: https://doi.org/10.1016/S2213-2600(13)70047-X

23. Slebos DJ, Klooster K, Ernst A, Herth FJ, Kerstjens HA. Bronchoscopic lung volume reduction coil treatment of patients with severe heterogeneous emphysema. Chest. 2012;142(3): 574582. doi: https://doi.org/10.1378/chest.11-0730

24. Klooster K, Ten Hacken NH, Franz I, Kerstjens HA, van Rikxoort EM, Slebos DJ. Lung volume reduction coil treatment in chronic obstructive pulmonary disease patients with homogeneous emphysema: A prospective feasibility trial. Respiration. 2014;88:116-125. doi: https://doi.org/10.1159/000362522

25. Vogelmeier CF, Criner GJ, Martinez FJ, et al. Global strategy for the diagnosis, management, and prevention of chronic obstructive lung disease 2017 Report: GOLD executive summary. Am J Respir Crit Care Med. 2017;195(5). doi: https://doi.org/10.1164/rccm.201701-0218PP

26. The National Emphysema Treatment Trial Research Group. Rationale and design of the National Emphysema Treatment Trial: A prospective randomized trial of lung volume reduction surgery. Chest. 1999;116(6):1750-1761. doi: https://doi.org/10.1378/chest.116.6.1750

27. Wanger J, Clausen JL, Coates A, et al. Standardisation of the measurement of lung volumes. Eur Respir J. 2005;26:511-522. doi: https://doi.org/10.1183/09031936.05.00035005

28. Miller MR, Hankinson J, Brusasco V, et al. Standardisation of spirometry. Eur Respir J. 2005;26:319-338. doi: https://doi.org/10.1183/09031936.05.00034805

29. American Thoracic Society. ATS statement: Guidelines for the six-minute walk test. Am J Respir Crit Care Med. 2002;166(1):111117. doi: https://doi.org/10.1164/ajrccm.166.1.at1102

30. Jones PW, Quirk FH, Baveystock CM. The St George's Respiratory Questionnaire. Respir Med. 1991;85(Suppl B):25-31.

31. Shah PL, Slebos DJ, Cardoso PF, et al. Bronchoscopic lungvolume reduction with Exhale airway stents for emphysema (EASE trial): Randomised, sham-controlled, multicentre trial. Lancet. 2011;378(9795):997-1005.

doi: https://doi.org/10.1016/S0140-6736(11)61050-7

32. Valipour A, Slebos DJ, Herth F, et al. Endobronchial valve therapy in patients with homogeneous emphysema. Results from the IMPACT Study. Am J Respir Crit Care Med. 2016;194(9):10731082. doi: https://doi.org/10.1164/rccm.201607-1383OC

33. Klooster K, ten Hacken NH, Hartman JE, Kerstjens HA, van Rikxoort EM, Slebos DJ. Endobronchial valves for emphysema without interlobar collateral ventilation. $N$ Engl J Med. 2015; 373: 2325-2335. doi: https://doi.org/10.1056/NEJMoa 1507807
34. Davey C, Zoumot Z, Jordan S, et al. Bronchoscopic lung volume reduction with endo-bronchial valves for patients with heterogeneous emphysema and intact interlobar fissures (the BeLieVeR-HIFi study): A randomised controlled trial. Lancet. 2015;386(9998):1066-1073.

doi: https://doi.org/10.1016/S0140-6736(15)60001-0

35. Come CE, Kramer MR, Dransfield MT, et al. A randomised trial of lung sealant versus medical therapy for advanced emphysema. Eur Respir J. 2015;46:651-662. doi: https://doi.org/10.1183/09031936.00205614

36. Watz H, Waschki B, Meyer T, et al. Decreasing cardiac chamber sizes and associated heart dysfunction in COPD: Role of hyperinflation. Chest. 2010;138(1):32-38.

doi: https://doi.org/10.1378/chest.09-2810

37. Vassaux C, Torre-Bouscoulet L, Zeineldine S, et al. Effects of hyperinflation on the oxygen pulse as a marker of cardiac performance in COPD. Eur Respir J. 2008;32:1275-1282. doi: https://doi.org/10.1183/09031936.00151707

38. Jorgensen K, Muller MF, Nel J, Upton RN, Houltz E, Ricksten $\mathrm{SE}$. Reduced intrathoracic blood volume and left and right ventricular dimensions in patients with severe emphysema: An MRI study. Chest. 2007;131(4):1050-1057. doi: https://doi.org/10.1378/chest.06-2245

39. Barr RG, Bluemke DA, Ahmed FS, et al. Percent emphysema, airflow obstruction, and impaired left ventricular filling. New Eng J Med. 2010;362:217-227. doi: https://doi.org/10.1056/NEJMoa0808836

40. Lammi MR, Ciccolella D, Marchetti N, Kohler M, Criner GJ. Increased oxygen pulse after lung volume reduction surgery is associated with reduced dynamic hyperinflation. Eur Respir J. 2012; 40: 837-843.

doi: https://doi.org/10.1183/09031936.00169311

41. Jorgensen K, Houltz E, Westfelt U, Nilsson F, Schersten H, Ricksten SE. Effects of lung volume reduction surgery on left ventricular diastolic filling and dimensions in patients with severe emphysema. Chest. 2003;124(5):1863-1870. doi: https://doi.org/10.1378/chest.124.5.1863

42. Come CE, Divo MJ, San Jose Estepar R, et al. Lung deflation and oxygen pulse in COPD: Results from the NETT randomized trial. Respir Med. 2012;106(1):109-119. doi: https://doi.org/10.1016/j.rmed.2011.07.012

43. Clarenbach CF, Sievi NA, Brock M, Schneiter D, Weder W, Kohler M. Lung volume reduction surgery and improvement of endothelial function and blood pressure in patients with chronic obstructive pulmonary disease. A randomized controlled trial. Am J Respir Crit Care Med. 2015;192(3):307-314. doi: https://doi.org/10.1164/rccm.201503-0453OC 
44. Mineo TC, Pompeo E, Rogliani P, et al. Effect of lung volume reduction surgery for severe emphysema on right ventricular function. Am J Respir Crit Care Med. 2002;165(4):489-494. doi: https://doi.org/10.1164/ajrccm.165.4.2108129

45. Zoumot Z, LoMauro A, Aliverti A, et al. Lung volume reduction in emphysema improves chest wall asynchrony. Chest. 2015;148(1):185-195.

doi: https://doi.org/10.1378/chest.14-2380

46. Faisal A, Zoumot Z, Shah PL, Neder JA, Polkey MI, Hopkinson NS. Effective bronchoscopic lung volume reduction accelerates exercise oxygen uptake kinetics in emphysema. Chest. 2016;149(2):435-446.

doi: https://doi.org/10.1378/chest.15-0404 